InterSedes, Revista electrónica de las sedes regionales de la Universidad de Costa Rica, ISSN 2215-2458, Vol XXI, Número 44, Agosto - Diciembre, 2020.

10.15517/isucr.v21i44.43924 | intersedes.ucr.ac.cr | intersedes@ucr.ac.cr

\title{
BIOPOLÍTICA Y ESCASEZ ALIMENTARIA EN LAS PLANTACIONES BANANERAS: EL CASO DE MAMITA YUNAI, DE CARLOS LUIS FALLAS, BANANOS, DE EMILIO QUINTANA, Y PRISIÓN VERDE, DE RAMÓN AMAYA
}

\author{
BIOPOLITICS AND FOOD SHORTAGES IN BANANA PLANTATIONS: THE CASE \\ OF MAMITA YUNAI, CARLOS LUIS FALLAS, BANANOS, EMILIO QUINTANA, AND \\ PRISIÓN VERDE BY RAMÓN AMAYA
}

Dorde Cuvardic-García ${ }^{1}$ Rubén Martínez-Barbáchano²

\begin{abstract}
"Cuando veo fincas enfermas, me acuerdo de nosotros, los campeños; me parece que allí estamos retratados en cuerpo entero, porque aquí, compañero, todos estamos enfermos, unos de sigatoka y otros de 'mata muerta', paludismo y tisis. Algunos curarán, si se largan a tiempo, otros: ¡ya sólo el hoyo! ¿Me ve uste? Soy un cadáver. Antes era un hombre macizo, como uste. Ahora, míreme, apenas tengo fuerzas para levantar la 'escopeta' y regar." (Ramón Amaya Amador, Prisión verde, 1974: 7).
\end{abstract}

\section{Resumen}

Existen diversas modalidades de escasez alimentaria. Una de ellas procede de las condiciones de explotación laboral de los trabajadores en las plantaciones bananeras. Esta situación se representa en Mamita Yunai, Bananos y Prisión verde. El control de los cuerpos de los trabajadores perteneciente al ámbito de la biopolítica, desde Foucault- se expresa, entre otras prácticas de la empresa transnacional capitalista, a través del monopolio de la distribución y consumo de los alimentos los trabajadores. El sometimiento o la rebelión hacia estas prácticas de control de la alimentación son dos posibilidades que se le ofrecen a los peones bananeros.

\footnotetext{
1 Profesor, Universidad de Costa Rica, San Pedro, San José, Costa Rica. Email: Dorde.Cuvardic@ucr.ac.cr

2 Profesor Universidad de Costa Rica, San Pedro, San José, Costa Rica Email: ruben.martinezbarbachano@ucr.ac.cr
} 


\title{
Palabras clave
}

Novela bananera; novela costarricense; novela nicaragüense; novela hondureña; escasez alimentaria; biopolítica.

\begin{abstract}
There are different modalities of food shortage. One of them derives from the conditions of labor explotations of workers in banana plantations. This situation is represented in Mamita Yunai, Bananos, and Prision verde. The control over the bodies of the workers-following Foucault's concept of biopolitics - is expressed, among other practices of the capitalist transnational corporation, through the monopoly of the distribution and consumption of food. The submission to or rebellion against these practices of food control are the two possibilities that banana plantation workers have at their disposal.
\end{abstract}

\section{Key words}

Banana Plantation Novel; Costa Rican Novel; Nicaraguan Novel; Honduran Novel; Food Shortage; Biopolitics.

\section{Introducción}

La escasez alimentaria cuenta con una gran tradición en la ficción literaria. Pero, ¿qué podemos entender por esta situación, prolongada en el tiempo, estructuramente hablando, y cómo podemos distinguirla del hambre? Involucra un acceso limitado a los alimentos y, como consecuencia, provoca desequilibrios alimenticios, desnutrición y hambre en el individuo y en la colectividad social. Como vemos, es un concepto que cuenta con implicaciones somáticas, sociales y económicas. La escasez alimentaria se produce cuando se limita la cantidad y la diversidad de los alimentos que ingiere el ser humano, por diversos motivos (bélicos, económicos, políticos, etc.). Este tema, junto con el hambre, comienza a ser trabajado por la crítica literaria como objeto principal de atención. Así, compilaciones sobre las relaciones entre la literatura y la comida incorporan el tema del hambre, como ocurre con las contribuciones que aportan Rodríguez Herrera (2013) y Pascual Soler (2013) en Comidas bastardas. Gastronomía, tradición e identidad en América Latina, editada por Ángeles Mateo del Pino y Nieves Pascual Soler.

Si indagamos un poco, podemos ofrecer una tipología de las representaciones literarias de la escasez alimentaria estructurada a partir de la situación que la origina. En primer lugar, podemos identificar la escasez motivada por una situación bélica. En Gerona (1874), una de las novelas de la primera serie de los Episodios nacionales, de Benito Pérez Galdós, los personajes se enfrentan al hambre que ocasiona el asedio a esta ciudad catalana durante la Guerra de la Independencia 


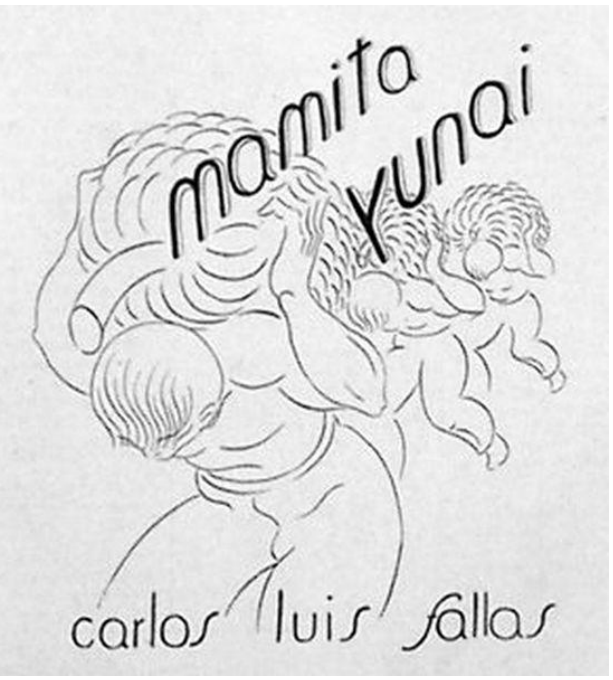

Afiche promocional de la novela Mamita Yunai en el Semanario Trabajo (1941). En: https:// commons.wikimedia.org/wiki/File:Fallas_Mamita_Yunai_-Trabajo,_1941.jpg contra las tropas napoleónicas. En esta oportunidad, se produce una escasez alimentaria provocada por el sitio del ejército francés, de la que no se salvan aquellos individuos que cuentan con los medios económicos suficientes como para sufragar los exorbitantes precios que alcanzan los escasos víveres, objeto de estaperlo. Otro motivo de escasez alimentaria proviene de las situaciones de postguerra, cuando los paises todavía no han 'normalizado' o regularizado el proceso de producción y distribución del consumo cotidiano de los alimentos. Innumerables relatos ofrecen el trasiego de las cartillas de racionamiento en estos periodos,

inmediatamente posteriores a las guerras. En algunas escenas de La Colmena (1951), de

Camilo José Cela, por ejemplo, queda tematizada la escasez alimentaria que sufre España después de la Guerra Civil (1942), cuando el resto de Europa se encuentra inmersa en la II Guerra Mundial. En tercer lugar, también podemos hablar de la escasez alimentaria que, en tiempos de paz, sufren aquellas personas y familias que disfrutaron en el pasado de bienestar económico y que, en el presente, viven bajo restricciones en el presupuesto familiar. Es lo que ocurre en la novelística de Benito Pérez Galdós en diversas ocasiones, como en La fontana de oro (1870), con las limitaciones que sufren las hermanas Porreño. Otro ejemplo, en la novelística de Galdós, en numerosas oportunidades, lo tenemos en los cesantes y sus familias, cuyas restricciones presupuestarias se evidencian, en primera instancia, en los alimentos que tienen que llevarse día tras día a la boca. El ejemplo más conocido del cesante nos lo ofrece la novela Miau (1888). Se encuentra motivada esta escasez por el declive económico de unas familias nobiliarias, burguesas o pequeño burguesas que, antes que perder su status social, prefieren aparentar y gastar en lujos, limitando su alimentación. En cuarto lugar, los largos viajes por mar o por tierra también provocaban la escasez alimentaria y la consiguiente aparición de enfermedades, y así se relataba en numerosos relatos de viajes y novelas de aventuras, géneros discursivos del ideario imperialista. Recordemos el escorbuto que 
sufrían muchos marineros, motivado por la ausencia de Vitamina $\mathrm{C}$ durante las largas travesías. Por último, la escasez alimentaria puede estar motivada por la pobreza, en personajes como obreros, chicos de la calle o pícaros, cuya deficiente entrada de ingresos económicos les impide acceder a los alimentos.

La escasez alimentaria es un tema recurrente del subgénero de la novela bananera latinoamericana, así como de otras modalidades de novela del realismo social del subcontinente (novela minera, por ejemplo). En el caso particular de la novela bananera, se da la siguiente situación paradójica: mientras la empresa transnacional comercializa el monocultivo (principalmente, frutas), con el que alimenta a una parte importante del mundo occidental a precios más o menos asequibles, los empleados que trabajan en su cosecha sufren de desnutrición, al recibir una alimentación monótona y desbalanceada: cuando surge el sistema de plantación, el cultivo de alimentos de primera necesidad en las pequeñas fincas de propiedad privada es sustituido por monocultivos dedicados a la exportación. Además, si nos enfocamos en el ámbito del consumo, los trabajadores sufren la comercialización de productos caros de primera necesidad -muchos de ellos, alimentos- en los comisariatos locales.

La imagen de América como tierra tropical exuberante y fértil domesticada por el proceso civilizatorio -a través del establecimiento de monocultivos que insertan a la región en la economía global- encuentra su máxima mistificación en los sombreros de frutas de la actriz Carmen Miranda, actualización del clásico cuerno de la abundancia. El discurso eurocéntrico patriarcal asocia a la mujer no occidental con la comida. Ambas -mujer y comida- son consideradas como objeto de disfrute y consumo. De esta manera, la Otredad humana no occidental queda asociada, en el discurso imperialista, al mundo vegetal. En el publicitario, como vemos en numerosos afiches de productos como el chocolate o las frutas, el mestizo o el negro es el sujeto que ofrece la abundancia tropical al resto del mundo: es el sujeto que la cosecha o sirve. La mistificación del enorme sombrero de bananos que sostiene sin ningún problema Carmen Miranda sobre su cabeza contrasta con la realidad de los racimos de bananos que cargan sobre sus espaldas los trabajadores de las bananeras a duras penas, momento que recoge el conocido dibujo promocional, de carácter documental, de la novela Mamita Yunai (1941), de Carlos Luis Fallas, publicado en el semanario Trabajo (1941), motivo iconográfico que también aparece en la ilustración de la portada de la Editorial Platina, en la edición de 1956. Estos obreros de la plantación son los tamemes de la economía capitalista transnacional. 
$\mathrm{Si}$ existe un género narrativo que traspase las fronteras nacionales en la literatura latinoamericana del siglo XX, este será el de la novela bananera, que denuncia un sistema de explotación sistemática del ecosistema y del ser humano establecido alrededor de las costas de Centroamérica y de las islas del Mar Caribe. Una de las denuncias de esta modalidad de novela latinoamericana es, precisamente, el hambre y la escasez alimentaria que sufren los trabajadores. La gastronomía y el arte culinario, presentes en los textos literarios que tematizan los banquetes de la burguesía, quedan sustituidos por la crisis alimentaria sufrida permanentemente por los sectores subalternos de la sociedad, los trabajadores de la bananera.

La novela bananera, cuya orientación pragmática es la denuncia, ha proliferado en aquellos países en los que estuvo consolidada la plantación de este producto. La dimensión transnacional del modelo productivo del monocultivo se materializó, desde un punto de vista geográfico, en una suerte de imperio económico -dominado por la United Fruit Company- que abarcó desde las costas de Honduras, Nicaragua, Costa Rica y Panamá en el Caribe hasta sectores del Pacífico salvadoreño y guatemalteco, y para el caso insular, Santo Domingo, Jamaica e islas de las Antillas menores.

Como consecuencia de su intencionalidad didáctica y propagandística, estas novelas, en una manifestación más de homología o adecuación entre la forma y el contenido -lo que en la poética clásica se conocía como decoro estilístico- emplean la estética del realismo social. Si se pretende denunciar un estado de cosas, una problemática política y económica, se parte del supuesto de que el texto tiene una génesis, un anclaje, en la realidad social.

Para profundizar el tema de la escasez alimentaria, me concentraré en este artículo en tres novelas centroamericanas: Mamita Yunai (1941), del costarricense Carlos Luis Fallas, Bananos. La vida de los peones de la yunai (1942), del nicaragüense Emilio Quintana, y Prisión verde (1950), del hondureño Ramón Amaya Amador ${ }^{3}$. Se trata de una escasez ocasionada por la explotación laboral y las paupérrimas condiciones salariales del sistema productivo agroexportador.

\footnotetext{
${ }^{3}$ ¿Qué novelas pertenecen al género de la novela bananera? Según Grinberg y Mackenbach (2006: 161-176), además de la novela de Carlos Luis Fallas, han sido tradicionalmente consideradas como novelas bananeras Sangre en el trópico (1930) del nicaragüense Hernán Robleto, Bananos y hombres (1931) de Carmen Lyra, Bananos. La vida de los peones de la yunai (1942), de Emilio Quintana, Prisión verde (1950) y Destacamento Rojo (1967), del hondureño Ramón Amaya Amador, Viento fuerte (1950), El papa verde (1954) y Los ojos de los enterrados (1960), trilogía de Miguel Ángel Asturias, Barro (1951), de Paca Navas de Miralda, Flor de Banana (1970), de Joaquín Beleño y Trópico (1971), de Marcos Carias Reyes.
} 
La hipótesis que planteo en este artículo es que las empresas agroexportadoras, con la connivencia del Estado, ejercen parte del control sobre sus trabajadores a través de la administración de los alimentos que pueden comprar, preparar y/o ingerir. Mediante el concepto de biopolítica, Michel Foucault (2009) se refiere al control social ejercido sobre el cuerpo de los individuos, más allá del manifestado por la ideología mediante la persuasión, sobre la conciencia del sujeto social. Diego Soto (2015: 176) sintetiza las implicaciones semánticas de este término al precisar que la vida, desde este enfoque, "es un objeto particular sobre el cual se aplica un poder político que enfrenta la vida, la transforma, la limita, la administra, decide sobre sus horizontes de posibilidad".

Más adelante expone ejemplos de las áreas de acción en las que interviene la biopolítica: "Se ocupa de fenómenos como la natalidad, la mortalidad, la tasa de reproducción, la fecundidad, la endemia [...], las diversas incapacidades biológicas, los efectos del medio ambiente-territorio sobre la salud y la producción; las tasas de criminalidad, desempleo y empleo, y patrones de consumo." (Soto, 2015: 185-6). Son formas de biopolítica y biopoder la medicina, al intervenir sobre el cuerpo del enfermo, y la industria del entretenimiento, mediante una serie de dispositivos ambientales y tecnológicos orientados a disciplinar el cuerpo del espectador. Pero también lo es, en el ámbito productivo, el control ejercido sobre el cuerpo de los trabajadores, en particular, el ejercido sobre los 'linieros' ('campeños', en el caso hondureño) por las empresas bananeras a la hora de decidir qué alimentos deben consumir, en particular al controlar los comisariatos y los comedores de los obreros agrícolas. El poder disciplinario de la empresa transnacional -en connivencia con el Estado- se ejerce mediante dispositivos de control alimentario que inciden directamente sobre el cuerpo del trabajador. Asumo en este artículo que no sólo el Gobierno es un actor biopolítico, sino también las empresas transnacionales agroexportadoras, que en ciertos momentos de la historia latinoamericana ha llegado a sustituir a los gobiernos. Biopolítica y geopolítica, en consecuencia, son dos prácticas de ejercicio del poder de las compañías bananeras sobre los ciudadanos de los Estados Centroamericanos. Las rutas comerciales y las redes de transporte, ferrocarril y telégrafo, propiedad de esta compañía, se desplegaban en el territorio de los estados caribeños donde emprendía sus operaciones. A través de todos estos dispositivos de la modernidad tecnológica controlaba la vida cotidiana de los centroamericanos.

Las empresas transnacionales agroexportadoras se encargan de administrar la escasez alimentaria en sus enclaves, de la misma manera que los gobiernos organizan la escasez 
alimentaria, mediante cupones y cartillas de racionamiento, en periodos bélicos y post-bélicos. Situaciones somáticas como el cuerpo extenuado o el cuerpo deshidratado proceden, en última instancia, de las decisiones económicas, financieras y laborales tomadas por la United Fruit Company al incentivar largas horas de trabajo, en condiciones climáticas adversas y alimentarias deplorables.

Ahora bien, el obrero bananero también cuenta con agentividad y puede reaccionar contra este control, contra este biopoder, por medio de protestas, huelgas, paros, etc. De hecho, ¿cuántos motines o revoluciones no se han producido, tanto en la realidad histórica como en las representaciones ficcionales literarias y cinematográficas, por la escasez alimentaria o por las políticas comerciales restrictivas impuestas a los alimentos? Recordemos el motín de la película $E l$ acorazado Potemkin (1925), de Sergei Eisenstein, motivado por el mal estado de la carne en un navío de la marina zarista. 'El pueblo quiere pan' suele ser el grito de protesta inicial de estas revueltas populares.

La escasez alimentaria en Bananos, Mamita Yunai y Prisión Verde

Las alusiones a la comida del trabajador de la zona bananera son más comunes en la segunda parte de Mamita Yunai (1941) que en la primera, que relata un caso de fraude electoral en la zona atlántica. Se refieren a las deplorables condiciones alimentarias que los trabajadores de la bananera sufren en el marco de los controles laborales ejercidos por la compañía. La regulación del horario de las comidas es uno de estos controles: "A las cuatro de la mañana debía estar la burra lista para todos; a las doce, el almuerzo; a las seis, la cena.” (en cursiva en el original) $(131)^{4}$. ¿En qué consiste la burra? En "un plato de avena que era la extra que acostumbraba el cabo, el montón de arroz y de frijoles revueltos y tostados que llamábamos 'gallo pinto' y los bananos sancochados." (131). Es, como se puede ver, una comida que carece de proteínas de origen animal. La denuncia de la novela bananera se expresa, entre otros focos de atención, por el registro testimonial y documental de la alimentación de los linieros en el mundo histórico centroamericano de la primera mitad del siglo XX.

\footnotetext{
${ }^{4}$ A partir de este momento, toda cita de la novela procede de la siguiente edición: Carlos Luis Fallas, Mamita Yunai, San José, Costa Rica, Editorial Costa Rica, 2013 [1941].
} 
También se describe esta regulación temporal de las comidas en Prisión verde (1942), del hondureño Ramón Amaya Amador. Los 'linieros' almuerzan a las 11 de la mañana, hora, asimismo, de descanso de las actividades laborales realizadas en la mañana: "los muchachos almuerceros repartían los alimentos a los hombres, quienes, ya con los platos y huacales en las manos sucias, buscaban las escasas sombras de los bananales." (94) ${ }^{5}$. Distribuyen la comida muchachos demasiado jóvenes para desempeñarse en el extenuante trabajo de la recogida de los racimos. Los horarios de las comidas forman parte de las prácticas de regulación del tiempo laboral. Se desayuna antes de ir al bananal, se almuerza durante la pausa laboral y se cena al terminar el día de trabajo. Recordando que la medición y la racionalización del tiempo es uno de los principales instrumentos de la modernidad económica y cultural, la regulación temporal del trabajo, del ocio y de las comidas forma parte, a su vez, del biopoder ejercido sobre el cuerpo del trabajador. Además, en Prisión verde, de Amaya Amador cuando los bananales de Culuco se silenciaban, aumentaba la actividad en los barracones, "cuyas cocinas humosas se transformaron en un hervidero de mujeres.” (59). Se estructura una división de la organización laboral desde el género: el trabajo en los bananales es masculino; en las cocinas, femenino.

La escasez y la desnutrición alimentaria de los trabajadores se combina, en aparente paradoja, con su consumo abusivo de bebidas alcohólicas -promovido por la empresa bananera-, que a su vez succiona el escaso salario de los trabajadores. En estos términos, motivo clásico de la novela bananera (es decir, situación prototípica) es la borrachera de los trabajadores. Desnutrición y alcoholismo son dos de las consecuencias, entre otras, sufridas por el cuerpo del trabajador, como se expone en Prisión verde, de Amaya Amador: "En la noche, la campeñería estaba convulsa; los vendedores de guaro hacían buen negocio. (...) El fuerte y terrible brebaje provocaba, en sus desnutridos cuerpos, un verdadero desastre; perdían la razón y, de sus huraños temperamentos, saltaba una agresividad inusitada que, muchas veces, concluía en hechos sangrientos." (161). El alcoholismo esclaviza al obrero agrícola en el círculo vicioso de trabajar por un salario que le permita comprar guaro y, además, contribuye a desactivar las redes sindicales. El capitalismo transcional, práctica canibal, emprende prácticas -ejercidas en el ámbito de la biopolítica- de consumición del cuerpo del trabajador. Marx (1976: 253) ya planteó en el capítulo VIII de $E l$

\footnotetext{
${ }^{5}$ A partir de este momento, toda cita de la novela procede de la siguiente edición: Ramón Amaya Amador, Prisión verde. (Pról. de Longino Becerra), Tegucigalpa: Editorial Ramón Amaya-Amador, 1974 (1950).
} 
capital la imagen del 'capital' como un vampiro que succiona el trabajo del obrero para obtener plusvalía.

Por contraste, las bebidas alcohólicas no están asociadas en la gerencia de las compañías bananeras a la escasez y el alcoholismo, sino a la opulencia, la distinción y el prestigio. En Prisión verde, refrescos (coca-cola) (34) y bebidas alcohólicas (whisky-and-soda) (34 y 36) son consumidos por los altos mandos de la empresa sin menoscabo de su alimentación. Por lo demás, las bebidas alcohólicas y la comida forman parte de las dádivas otorgadas por la Compañía Frutera a los propietarios que pretenden convencer para que vendan sus tierras a la transnacional, en lo que podríamos ver una actualización de las engañosas prácticas colonialistas de 'comprar' la tierra de las culturas originarias mediante la venta de artículos occidentales de escaso o nulo valor (tierras por collares). El narrador de Prisión Verde, en estilo indirecto libre, accede a la inocente complacencia con la que dos terratenientes locales interpretan el supuesto trato dadivoso que reciben de empresa: "Para ellos, terratenientes del Valle, la Compañía no negaba nada en absoluto: carros expresos, pases de cortesía en los trenes, almuerzos, finos licores, atenciones a granel." (la cursiva es añadida) (29). Detrás de la cortesía del regalo, del don, de la deferencia, la cortesía y del trato equitativo se esconde la compra abusiva de la tierra a los propietarios locales.

La compañía bananera planifica un manejo estratégico del acceso a la comida y a la bebida: convertidas en un don o regalía, forma parte de la compra de tierras -a bajos precios- a los terratenientes locales; transformadas en un bien escaso, contribuyen a la consumición del cuerpo del trabajador, cuya muerte permitirá reponer el puesto laboral con otros 'linieros' que tengan las fuerzas suficientes para enfrentar las extenuantes jornadas. Así se plantea en una de las tantas intervenciones 'adoctrinadoras' del narrador de Prisión verde -digresiones comunes en la novela bananera-, al ver en los trabajadores de las bananeras "hombres y mujeres que van vendiendo por un par de monedas la energía de sus cuerpos y de sus vidas, en una constante lucha sin cuartel para obtener el pan negro y duro de cada día, bajo el signo verde y oro del banano." (60).

La escasez alimentaria conlleva, en la preparación de las distintas comidas, la utilización de los mismos ingredientes y la preparación de los mismos platos: la dieta del trabajador es monótona. En Prisión verde, la cocinera Plácida le lleve a Luján, "en un plato de loza Made in USA, frijoles, arroz y bananos sancochados. Además, un jarro de café negro, humeante." (en negrilla en el original) (67). Es decir, le sirve la famosa burra, ya mencionada previamente. Exactamente estos son los ingredientes que comen los 'linieros' en Mamita Yunai, de Carlos Luis 
Fallas. En la segunda parte de esta última novela, el narrador, Sibaja, retrata desde una intencionalidad irónica esta situación de escasez alimentaria. Según este personaje, la única diferencia que separa el almuerzo que le sirven a su peonada y a las demás es la sopa: "La Pastora nos servía en el almuerzo un poquito de sopa, frijoles, arroz y banano. Las otras peonadas se conformaban con banano, frijoles y arroz, y con arroz, frijoles y bananos." (136). Pero fijémonos en la comida de las demás peonadas. En la última frase se elabora un quiasmo, conocida figura de permutación o posición. En el quiasmo, recordemos, la posición de los términos de la primera parte o periodo de la oración se invierte, especularmente, en la segunda parte del enunciado. En el presente caso, la enumeración de la composición del almuerzo de las demás peonadas se ordena desde una estructura quiasmática, lectura en la que coincide Muñoz Solano (2010: 80): se trata de una enumeración donde se destaca la invariabilidad de la comidsa en un marco de escasez, ya que la única 'variedad' radica o consiste en la posibilidad que tiene el narrador -y ya no el trabajadorde cambiar el orden de los términos (de los ingredientes).

La simulación de la variedad de los alimentos ofrecidos a las peonadas se produce mediante la alteración del orden en el que se enumeran a la instancia lectora los ingredientes que forman parte de su almuerzo. En mi caso, asimismo, resalto el uso irónico de este quiamo por parte del narrador. La metátesis - o alteración del orden- de los términos incorporados en la enumeración de los productos, encaminada a ofrecer una disposición quiasmática de los términos- produce una ilusoria proliferación de ingredientes: 'se conformaban con banano, frijoles y arroz, y con arroz, frijoles y bananos'. Siempre se sirve lo mismo, por más que unas veces sean 'frijoles, arroz y banano'; otras, 'banano, frijoles y arroz' o, por último, 'arroz, frijoles y banano'. La aparente proliferación o abundancia lingüística alude irónicamente, desde el principio de la contradicción, a la pobreza del referente alimenticio.

La comida de los trabajadores negros difiere de la ingerida por los trabajadores y los capataces. El narrador la describe desde la alteridad, pero siempre se caracteriza por la escasez. En Mamita Yunai se resume, desde la temporalidad iterativa (cotidiana, día tras día), la alimentación de los trabajadores afrocaribeños: "Llevaban al trabajo su miserable comida en un tarro: ñame, yuca, ñampí y bananos, todo arreglado con aceite de coco; algunas veces arroz y 'calalú, un planta moradita que se cría en el monte y que solo ellos saben cocinar y comer.' (152). A primera vista, parece una comida que ofrece una mayor variedad en sus ingredientes. Forma parte del encuadre de la alteridad empleado por el narrador el hecho de que preste atención al 'modo 
de preparación y de ingestión' de los alimentos por parte de los trabajadores afrocaribeños. En el caso de la población afroantillana, el modo de ingestión de la comida preparada, según el narrador, está caracterizado por la ausencia de protocolo o decoro, conducta esta última que, implícitamente, caracterizaría al resto de los trabajadores de la bananera: "Si hacía sol, encendían un fogón para calentarla; si llovía a cantaros, se la tragaban fría, tapándose con una hoja de banano para que no se les llenara de agua el tarro. Comían a puños, limpiando el fondo del tarro con sus rudos dedazos, y después bajaban la comida con un cabo de caña" (152).

En esta última novela, para enfrentar la monotonía de la comida y la escasez de los comisariatos, Sibaja y su grupo de peones capturan regularmente peces de río mediante el empleo de dinamita, procedimiento que destruye el medio ambiente. A diferencia de la comida ofrecida por la bananera, la aportada por la naturaleza se caracteriza por la abundancia, que Sibaja enumera desde la amplificación lingüística. Ve en los peces una comida suculenta, valor expresado mediante el detalle y la demora complaciente con que los describe. Esta es una evidencia que nos permite inferir que, para este personaje, constituyen un objeto de deseo de primer orden. La vividez de la descripción alude, por defecto, al hambre y a la necesidad de saciar este último con proteínas que brillan por su ausencia en la alimentación cotidiana del 'liniero':

"Con los bobos iban los tepemechines, medianos y lambuzos, de escamas menuditas y grisáceas; las escasísimas guabinas, punteadas hacia la cola y cabezonas, con cerdas gruesas en el ancho hocico y una bolsa blancuzca y pegada en la barriga; y los roncadores, lisos y plateados. Y allá de vez en cuando un róbalo, de carne tan delicada que no lo podíamos dejar para otro día ni en salmuera, y que era uno de los pejes más bien criados que encontrábamos en el río." (en cursiva en el original) (137-138).

Por otra parte, el peón bananero gasta parte importante de su salario en la adquisición o compra de comida en el comisariato o en pagar la comida preparada por las cocineras y cocineros. Así, en Bananos, de Emilio Quintana, el narrador precisa que después de pagar su comida, le quedan al peón cuatro pesos diarios (30). Se consume rápidamente el salario en una alimentación deficiente que consume, a su vez, el cuerpo del trabajador. Contratistas, intermediarios y capataces 
imponen su voluntad, entre otras medidas, regulando qué, cuándo y a qué precio comen los trabajadores. Controlan los comisariatos (la distribución de los alimentos) y los comedores colectivos (la preparación y la ingestión de las comidas): "Ganábamos seis colones por día y se gastaban dos en comida. Pero aquella cataplasma de arroz sin gota de manteca y aquellos frijoles fritos en 'su propia sangre', obligaban al comensal a gastar algo más en "extras" de café negro con pan y agua de azúcar. Era un sistema impuesto por la compañía.” (41).

Detonante del conflicto social en la novela bananera -y como mecanismo de desarticulación del sentimiento de comunidad entre los trabajadores- es el reparto de los alimentos. Durante el reparto, la monotonía de la comida y el uso de ingredientes podridos provoca las protestas de los trabajadores, de manera similar a los reclamos de los marinos del ejército zarista en la ya mencionada película El acorazado Potemkin (1925), de Sergei Eisenstein, donde el capitán del barco, en actitud cínica, niega que la carne esté llena de gusanos. Una primera protesta sobre la mala calidad de la comida ofrecida a los peones en la novela bananera procede de Mamita Yunai: “-iQué comida la que da ese chancho! -comentó Calero, echándose un puñado de arroz a la boca y refiriéndose a Azuola-. ¡Así quién no si’hace'e plata! Una pelota di’arroz y frijoles, cuatro bananos y un tuquillo'e dulce negro y revenío." (en cursiva en el original) (172). Otra protesta de los peones contra la mala calidad de la comida que les proporciona la compañía procede de Bananos, de Emilio Quintana:

"Al medio día el almuerzo nos llegaba al lugar de trabajo. Y al repartir la comida siempre se registraban pleitos porque el cocinero, un invertido sinvergüenza, tenía preferencias para algunos peones de la cuadrilla. Para resguardarse de los enojados, el cocinero confiaba en su ayudante, un mozalbete vigoroso y gruñón. También contaba con el apoyo del contratista. De ahí que el cocinero se tornara insolente. Una vez, después de estar comiendo frijoles hediondos en varios tiempos, uno de los trabajadores rechazó el plato, protestando:

-Estos frijoles están podridos.

Inmediatamente saltó el cocinero:

- ¡Jesús, mijito! (¿Querés jamón con huevos?)

-No es para tanto: quiero comida aseada. 
-Pues pa que saliste al monte... te hubieras metío en un nicho en tu casa y estarías bien tranquilo. Yo aquí pongo lo que me dan.

-No te dan frijoles podridos.

-Jesús, papa, pero se pudren en el caldero. Además, ya conoces el camino. Yo en cuanto venga el jefe le vó a decir que le estas espantando a la gente, pa que te corte el rabo." $(43)^{6}$.

De nuevo tenemos un caso de ironía, como ya vimos en Mamita Yunai. En el primer caso, la escasez es disfrazada de abundancia. En el presente caso, la ironía proviene del cocinero: considera que el 'liniero' tiene exageradas pretensiones culinarias, alejadas de lo que debería esperar recibir el trabajador de parte de los cocineros de la compañía. De ahí su comentario irónico (un 'invertido' que tenía preferencias por algunos peones, según la perspectiva homofóbica del narrador, recordando que, desde el patriarcado, la cocina es un trabajo feminizado): ‘-¡Jesús, mijito! (¿Querés jamón con huevos?)'. El cocinero plantea su respuesta irónica como si accediera a sus reivindicaciones, como si asumiera su error y aceptara la posibilidad de ofrecer, a cambio, como reparo, comida de mejor calidad. El 'liniero', en realidad, protesta ante una situación de escasez alimentaria que niega el derecho del trabajador a recibir una comida digna. En este caso, el 'invertido' es el intermediario de los intereses de la empresa transnacional. La protesta que el trabajador exprese ante las deplorables condiciones higiénicas y alimentarias es interpretada por estos mandos medios (capataces, jefes de cocina) como signo de disidencia política (de rebelión).

En la novela bananera, la desnutrición y la insalubridad terminan, en muchos casos, en la muerte, provocada, más que todo, por enfermedades infecciosas de origen gástrico. Declara el narrador de Bananos, de Quintana, que la muerte "[e]s el debido cobro de las amebas, después que el infeliz se ha engullido de malas comidas y ha bebido el agua sucia de los criques." (en cursiva en el original) (Quintana, 1985: 35). Asimismo, en los comedores domina la suciedad y la insalubridad, como en los barracones de Culuco, en Prisión verde: "sobre las mesas destartaladas y mugrientas, hacían festines las moscas, bichos asquerosos y prolíficos para cuya destrucción no había suficiente insecticida." (55). La ausencia de higiene, combinada con una alimentación exigua, termina por convertir al trabajador en un sujeto enfermo y, finalmente, en un cadáver, en el marco

\footnotetext{
${ }^{6}$ A partir de este momento, toda cita de la novela procede de la siguiente edición: Emilio Quintana, Bananos, Managua, Nueva Nicaragua, 1985 [1942].
} 
InterSedes, N44. Vol XXI (2020). ISSN 2215-2458

de prácticas de exterminio del trabajador, rápidamente reemplazable por un sistema capitalista que 'engulle' cuerpos para expulsar mercancías.

\section{Conclusiones}

La novela bananera denuncia una de las aparentes paradojas del capitalismo, situación que, en realidad, constituye un ejemplo de mala fe de carácter sistemático y global: las bananeras abastecen Occidente con un alimento, el banano, mientras dejan a los trabajadores de este cultivo en una permanente crisis alimentaria. La economía de la escasez, impuesta por las compañías bananeras, promueve la destrucción de los lazos solidarios entre los trabajadores: se destruye el cuerpo físico y el cuerpo social, los lazos solidarios, comunitarios, sindicales. La plusvalía capitalista favorece la miseria del trabajador, quien consume casi todo su salario en alimentos de subsistencia. La empresa bananera consume todo el salario del trabajador: el peón bananero queda sujeto a los precios ofrecidos en los comisariatos oficiales. Consecuencia de la escasez alimentaria, la desnutrición es una de las más importantes denuncias, en su función testimonial, de la novela bananera. Pero la alimentaria no es la única escasez imperante en esta modalidad de novela latinoamericana. Consecuencia de la escasez de vivienda es el hacinamiento, la ausencia de privacidad y las peleas entre trabajadores; consecuencia de la ausencia de higiene, las enfermedades. El cuerpo consumido y aniquilado, hasta quedar convertido en cadáver, es el punto final del sufrimiento producido por los tres tipos de escasez: la alimentaria, la higiénica y la sanitaria. Un sistema económicamente perverso, enfermo, producirá cuerpos desechables y rápidamente intercambiables. El epígrafe que encabeza La prisión verde, al inicio del presente artículo, pretende sintetizar este proceso, la explotación del trabajador.

\section{Bibliografía}

Amaya Amador, R. (1967). Destacamento Rojo. Tegucigalpa: Editorial Universitaria. Universidad Nacional Autónoma de Honduras.

Amaya Amador, R. 1974 [1950]). Prisión verde (Pról. de Longino Becerra). Tegucigalpa: Editorial Ramón Amaya-Amador.

Asturias, M. A. (1950). Viento fuerte. Buenos Aires: Losada. 
Asturias, M. A. (1971 [1954]). El papa verde. Barcelona: Salvat.

Asturias, M. A. (1960). Los ojos de los enterrados. Buenos Aires: Losada.

Beleño, J. (1970). Flor de Banana. Panamá: Dirección de Cultura del Ministerio de Educación.

Carias Reyes, M. (1971). Trópico. Tegucigalpa: Universidad Nacional Autónoma de Honduras.

Del Pino, A. M. y N. Pascual Soler (eds). (2013). Comidas bastardas. Gastronomía, tradición e identidad en América Latina. Edición e introducción de Santiago, Chile: Editorial Cuarto Propio.

Fallas, C. L. (1956 [1941]). Mamita Yunai. Buenos Aires: Editorial Platina.

Fallas, C. L. (2013 [1941]). Mamita Yunai. San José, Costa Rica: Editorial Costa Rica.

Foucault, M. (2009). Biopolítica. Nacimiento de la biopolítica. Curso del Collège de France (19781979). Edición establecida por Michel Senellart, bajo la dirección de François Ewald y Alessandro Fontana. Traducción: Horacio Pons. Madrid: Editorial Akal.

Grinberg Pla, V. y W. Mackenbach (2006). "Banana novel revis(it)ed: etnia, género y espacio en la novela bananera centroamericana. El caso de Mamita Yunai”, Iberoamericana. (23), pp. 161176.

Lyra, C. (1977). "Bananos y hombres”. En: Relatos escogidos. Prólogo, selección y notas de Alfonso Chase. San José: Editorial Costa Rica, pp. 371-287.

Marx, K. (1976). El capital. Crítica de la economía política. Libro I. El proceso de producción del capital. Barcelona: Grijalbo.

Muñoz Solano, N. 2018. "La lucha (de clases) de la cocina: los alimentos y la dialéctica de la apetencia en la novela Mamita Yunai de Carlos Luis Fallas”, Revista de Filología y Lingüística (Universidad de Costa Rica), 44 (2): pp. 69-84.

Navas de Miralda, P. (1951). Barro. Guatemala: Ministerio de Educación Pública.

Pascual Soler, N. (2013). “'Tengo hambre’: breviario de una emoción”. En: del Pino, Ángeles Mateo y Nieves Pascual Soler (eds). Comidas bastardas. Gastronomía, tradición e identidad en América Latina. Edición e introducción de Santiago, Chile: Editorial Cuarto Propio, pp. 589-605. 
Pérez Galdós, B. (2008). Gerona. Madrid: Alianza editorial.

Pérez Galdós, B. (1997). Miau. Madrid: Alianza editorial.

Pérez Galdós, B. (1993). Novelas, I. La sombra. La Fontana de Oro. El audaz. Tormento. Madrid: Turner Libros.

Quintana, E. (1985 [1942]). Bananos. Managua: Nueva Nicaragua.

Robleto, H. (2000). Sangre en el trópico. Tegueste: Ediciones Baile del Sol.

Rodríguez Herrera, J. M. (2013). “Botas hervidas que se trinchan como si fueran pavos y pavos 'de un atractivo color dorado' que nadie trincha: un análisis de varias escenas de comida de La quimera del oro de Charles Chaplin. En: del Pino, Ángeles Mateo y Nieves Pascual Soler (eds). Comidas bastardas. Gastronomía, tradición e identidad en América Latina. Edición e introducción de Santiago, Chile: Editorial Cuarto Propio, pp. 503-517.

Semanario Trabajo. 1941. Afiche promocional de la novela Mamita Yunai. En: https:// commons.wikimedia.org/wiki/File:Fallas_-Mamita_Yunai_-Trabajo,_1941.jpg

Soto Morera, D. A. (2015). En carne propia. Religión y biopoder. San José, Costa Rica: Editorial Arlequín. 